\title{
Influence of apelin-12 on troponin levels and the rate of MACE in STEMI patients
}

\author{
Xhevdet Krasniqi $i^{*}$ (D) Blerim Berisha ${ }^{2}$, Masar Gashi ${ }^{2}$, Dardan Koçinaj ${ }^{2}$, Fisnik Jashari ${ }^{2}$ and Josip Vincelj ${ }^{1}$
}

\begin{abstract}
Background: During acute myocardial infarction, phosphorylated Tnl levels, $\mathrm{Ca}^{2+}$ sensitivity and ATPase activity are decreased in the myocardium, and the subsequent elevation in $\mathrm{Ca}^{2+}$ levels activates protease I (caplain I), leading to the proteolytic degradation of troponins. Concurrently, the levels of apelin and APJ expression are increased by limiting myocardial injury.

Methods: In this prospective observational study, 100 consecutive patients with ST-elevation acute myocardial infarction were included. Patients meeting the following criteria were included in our study: (1) continuous chest pain lasting for $>30 \mathrm{~min}$, (2) observation of ST-segment elevation of more than $2 \mathrm{~mm}$ in two adjacent leads by electrocardiography (ECG), (3) increased cardiac troponin I levels, and (4) patients who underwent reperfusion therapy. We evaluated the levels of apelin-12 and troponin I on the first and seventh days after reperfusion therapy in all patients.
\end{abstract}

Results: Apelin-12 was inversely correlated with troponin I levels (Spearman's correlation $=-0.40$ ) with a $p$ value $<0.001$. There was variability in the apelin values on the seventh day (Kruskal-Wallis test) based on major adverse cardiac events (MACE) $(p=0.012)$. Using ROC curve analyses, a cut-off value of $>2.2$ for the association of apelin with MACE was determined, and the AUC was 0.71 ( $95 \%$ Cl, 0.58-0.84). Survival analysis using the Kaplan-Meier method showed a lower rate of MACE among patients with apelin levels $>2.2(p=0.002)$, and the ROC curve analysis showed a statistically significant difference in the area under the curve $(p=0.004)$.

Conclusion: The influence of apelin levels on troponin levels in the acute phase of STEMI is inversely correlated, whereas in the non-acute phase, low apelin values were associated with a high rate of MACE.

Keywords: Apelin, Myocardial infarction, Major adverse cardiac events

\section{Background}

After acute myocardial infarction, the left ventricle undergoes a series of changes in shape, size, and thickness, which is referred to as ventricular remodelling; it precedes the development of clinically evident MACE by months to years. The apelin-APJ axis may be up-regulated with good left ventricular remodelling or down-regulated with cardiac troponin degradation and the release of cardiac natriuretic hormones that inhibit the pathophysiological mechanisms responsible for ventricular remodelling [1-3]. The role of hypoxia in the release of apelin, ischaemia reperfusion injury, and the action of apelin in cardiac contractility remains unclear.

\footnotetext{
* Correspondence: xhevdeti_16@hotmail.com

${ }^{2}$ University Clinical Center of Kosova, Mother Theresa n.n, 10000 Prishtina,

Republic of Kosovo

Full list of author information is available at the end of the article
}

\section{Apelin and the cardiovascular system}

The gene for the APJ receptor is located on chromosome 11 and encodes a G-protein coupled receptor that is recognized only by apelin $[4,5]$. APJ receptor expression is particularly high in the heart, lung, kidney, cerebellum and vascular endothelium. In the heart, this receptor is expressed on a number of cell types, including the endothelium, smooth muscle and myocytes. The apelin gene is located on the human $\mathrm{X}$ chromosome, which, in response to hypoxia, encodes a 77-amino-acid preproprotein that is cleaved by endopeptidases into a biologically active peptide such as apelin-12 [6]. The positive effects of apelin on the cardiovascular system include the regulation of vascular tone, cardiac contractile function and fluid balance [7-10]. Apelin plays a role in diuresis, pituitary 
hormone release, cardiomyocyte apoptosis and inflammation [11-14].

In acute myocardial infarction, the levels of troponins are predictors of MACE [15-17]. The use of a sensitive troponin I assay improves early diagnosis [18], and these patients are more likely to undergo angiography $[19,20]$.

\section{Relationship between apelin and troponin}

After the binding of apelin with its receptor, phospholipase $\mathrm{C}$ (PLC) is activated and generates inositol trisphosphate (IP3) and diacylglycerol (DAG) from phosphatidyl inositol bisphosphate (PIP2). Diacylglycerol activates protein kinase $\mathrm{C}$ (PKC), increasing the activity of the sarcolemmal $\mathrm{Na}^{+} / \mathrm{H}^{+}$exchanger (NHE). This leads to an elevation in $\mathrm{pH}$, which indirectly increases the intracellular $\mathrm{Ca}^{2+}$ concentration through the reverse $\mathrm{Na}^{+} / \mathrm{Ca}^{2+}$ exchanger (NCX). On the other hand, apelin increases intracellular $\mathrm{Ca}^{2+}$ concentration via the calcium release channels associated with ryanodine receptors (RyRs) and via the activation of protein kinase $C$, which decreases the phosphorylation of phospholamban (PLB), reducing the function of the SR Ca ${ }^{2+}$ ATPase (SERCA) [21, 22].

Through protein kinase $\mathrm{C}$, apelin activates its sites on troponin $\mathrm{I}$, thereby regulating $\mathrm{Ca}^{2+}$ sensitivity and ATPase activity in the myocardium (Fig. 1) [23, 24].

During ischaemia/infarction, phosphorylated TnI levels, $\mathrm{Ca}^{2+}$ sensitivity and ATPase activity are decreased in the myocardium, and subsequently, the elevated $\mathrm{Ca}^{2+}$ levels activate protease I (caplain I), which may lead to the proteolytic degradation of troponins [25-28]. Concurrently, the levels of apelin and APJ expression are increased by limiting myocardial injury [1].
The aims of this study were to evaluate the influence of apelin on troponin levels and the rate of major adverse cardiac events (MACE) in STEMI patients.

\section{Methods \\ Study population}

In this dual-centre, prospective observational study, one hundred consecutive patients with ST-elevation acute myocardial infarction who presented or were referred to the coronary care unit of our institutions were included. Patients meeting the following criteria were included in our study: (1) continuous chest pain lasting $>30 \mathrm{~min}$, (2) the observation of ST-segment elevation of more than $2 \mathrm{~mm}$ in two adjacent leads by electrocardiography (ECG), (3) increased cardiac troponin I levels, and (4) patients who underwent reperfusion therapy [29]. We evaluated the levels of apelin-12 and troponin I on the first and seventh days after reperfusion therapy in all patients. The study was approved by the institutional ethics committee of Dubrava University Hospital-Zagreb and the University Clinical Center of Kosova-Pristina. Written informed consent was obtained from all patients before inclusion in the study.

\section{Patient characterization}

Demographic data and clinical history were obtained during hospitalization using a standardized questionnaire. Based on coronarography, the number of diseased vessels, culprit lesions and stenoses was determined. The culprit lesion was defined as the lesion with the highest degree of stenosis or with angiographic signs of endoluminal thrombi and/or plaque rupture. Stenoses $\geq 50 \%$ of the lumen of the left main artery (LMA) or $\geq 70 \%$ of

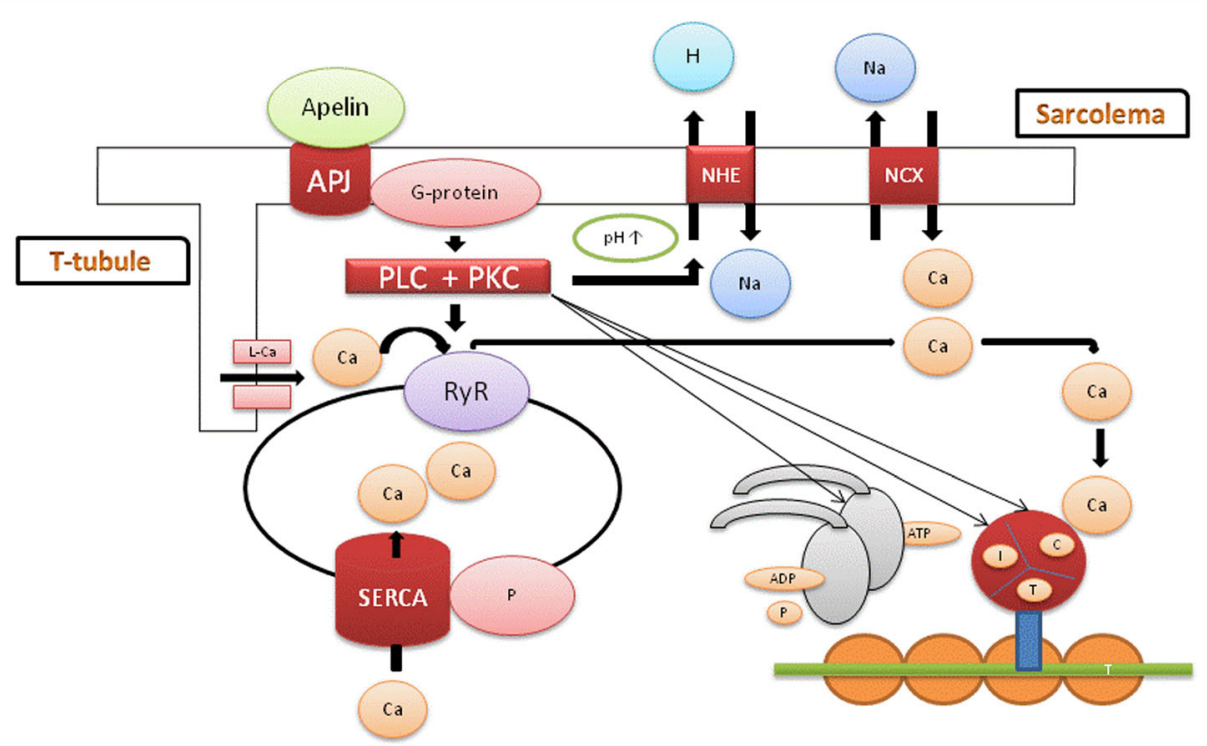

Fig. 1 Influence of apelin on troponin 
the lumen of major epicardial vessels were considered significant. For the assessment of LV ejection fraction, transthoracic echocardiography was performed in all patients during their hospitalization.

\section{Laboratory data}

Blood samples for the measurement of routine laboratory parameters were collected at admission. On the first and seventh day after reperfusion therapy, blood samples were collected into lavender Vacutainer tubes (Catalogue No. VT-6450) that contain EDTA and can collect up to $7 \mathrm{ml}$ of blood/tube. The blood was transferred from the lavender vacutainer tubes to centrifuge tubes containing aprotinin $(0.6 \mathrm{TIU} / \mathrm{ml}$ of blood) and then centrifuged at $1600 \mathrm{xg}$ for $15 \mathrm{~min}$ at $4{ }^{\circ} \mathrm{C}$. The serum was aliquoted and stored at -80 degrees Celsius to prevent degradation. Circulating apelin-12 and troponin I concentrations were analysed using a commercially available enzyme-linked immunosorbent assay (ELISA) kit (Phoenix Pharmaceuticals, Inc) according to the manufacturer's instructions.

\section{Statistical analysis}

The primary endpoint of the study was the influence of apelin-12 on troponin levels and its association with major adverse cardiac events in STEMI patients. Continuous variables are presented as the mean \pm standard deviation or as the median (range), whereas categorical variables are presented as percentages. Spearman's correlation was used to analyse the degree of association between apelin-12 and troponin I, whereas ROC curve analyses were used to determine a cut-off value of apelin-12 for an association with MACE. Using KaplanMeier estimates, we evaluated the association between apelin and future MACE after a follow-up period of 12 months. All statistical analyses were performed using SPSS statistics version 21 .

\section{Results}

\section{Patient characteristics}

Baseline characteristics of the study population are displayed in Table 1 . The mean age was $60.52 \pm 11.50$ years old ( $60 \%$ male). Coronary risk factors and laboratory values are presented as a mean, median or percentage. In terms of coronary angiographic findings, the culprit artery was the left anterior descending artery (LAD, $48 \%$ ), right coronary artery (RCA, $40 \%$ ) and circumflex (12\%), whereas, in terms of vessel disease, $40 \%$ of patients had one-vessel disease, $31 \%$ had two-vessel disease and $29 \%$ had three-vessel disease.

\section{Relationship between apelin and troponin}

The degree of association between apelin-12 and troponin I in the first day of the acute phase of STEMI was
Table 1 Baseline characteristics of patients

\begin{tabular}{|c|c|}
\hline \multicolumn{2}{|l|}{ Parameters } \\
\hline Age (year), mean $( \pm S D)$ & $60.52 \pm 11.50$ \\
\hline Gender (male), $n$ (\%) & $60(60)$ \\
\hline \multicolumn{2}{|l|}{ Medical history } \\
\hline Hypertension, $n(\%)$ & $59(59)$ \\
\hline Diabetes mellitus, $n(\%)$ & $19(19)$ \\
\hline Dyslipidemia, n (\%) & $32(32)$ \\
\hline Smoking, $n(\%)$ & $32(32)$ \\
\hline Family history of cardiovascular disease, $n(\%)$ & $20(20)$ \\
\hline Killip class >1, n (\%) & $13(13)$ \\
\hline Ejection fraction, mean $( \pm S D)$ & $50.34 \pm 10.20$ \\
\hline \multicolumn{2}{|l|}{ Laboratory values } \\
\hline Haemolobin $(\mathrm{g} / \mathrm{dL})$, mean $( \pm \mathrm{SD})$ & $13.54 \pm 1.39$ \\
\hline Creatinine (umol/L), median (range) & $92.90(67.21-124.34)$ \\
\hline $\begin{array}{l}\text { Apelin } 12 \text { on the first day }(\mathrm{ng} / \mathrm{mL}) \text {, } \\
\text { median (range) }\end{array}$ & $2.98(0.45-15.25)$ \\
\hline $\begin{array}{l}\text { Apelin } 12 \text { on the seventh day }(\mathrm{ng} / \mathrm{mL}) \text {, } \\
\text { median (range) }\end{array}$ & $2.33(0.26-10.90)$ \\
\hline $\begin{array}{l}\text { Troponin I on the first day }(\mathrm{ng} / \mathrm{mL}) \text {, } \\
\text { mean }( \pm S D)\end{array}$ & $54.80 \pm 60.99$ \\
\hline $\begin{array}{l}\text { Troponin I on the seventh day }(\mathrm{ng} / \mathrm{mL}) \text {, } \\
\text { mean }( \pm \mathrm{SD})\end{array}$ & $12.43 \pm 24.48$ \\
\hline \multicolumn{2}{|l|}{ Coronary angiographic findings } \\
\hline \multicolumn{2}{|l|}{ Culprit lesion, $n(\%)$} \\
\hline RCA & $40(40)$ \\
\hline LAD & $48(48)$ \\
\hline LCX & $12(12)$ \\
\hline \multicolumn{2}{|l|}{ Vessel disease, $n(\%)$} \\
\hline 1 & $40(40)$ \\
\hline 2 & $31(31)$ \\
\hline 3 & $29(29)$ \\
\hline
\end{tabular}

Values are $n(\%)$, mean ( \pm SD) or median (range)

Abbreviations: $R C A$ right coronary artery, $L A D$ left anterior descending coronary artery, $L C x$ left circumflex coronary artery

analysed with Spearman's correlation $=-0.40(p<0.001)$. Based on the regression analysis of the relationship between apelin-12 and troponin I, one variable could be predicted from the other (Fig. 2).

\section{Apelin and major adverse cardiac events}

There was variability in the apelin values on the seventh day (Kruskal-Wallis test) in relation to major adverse cardiac events (MACE) that was significantly different $(p<0.012)$. Kaplan-Meier curves were used to show the number of MACE and the proportion of patients that survived at each event time point based on the cutoff value of apelin-12 on the seventh day $(2.2 \mathrm{ng} / \mathrm{mL})$ (Fig. 3). The log-rank test for the difference in survival resulted in a $p$ value of 0.002 . 


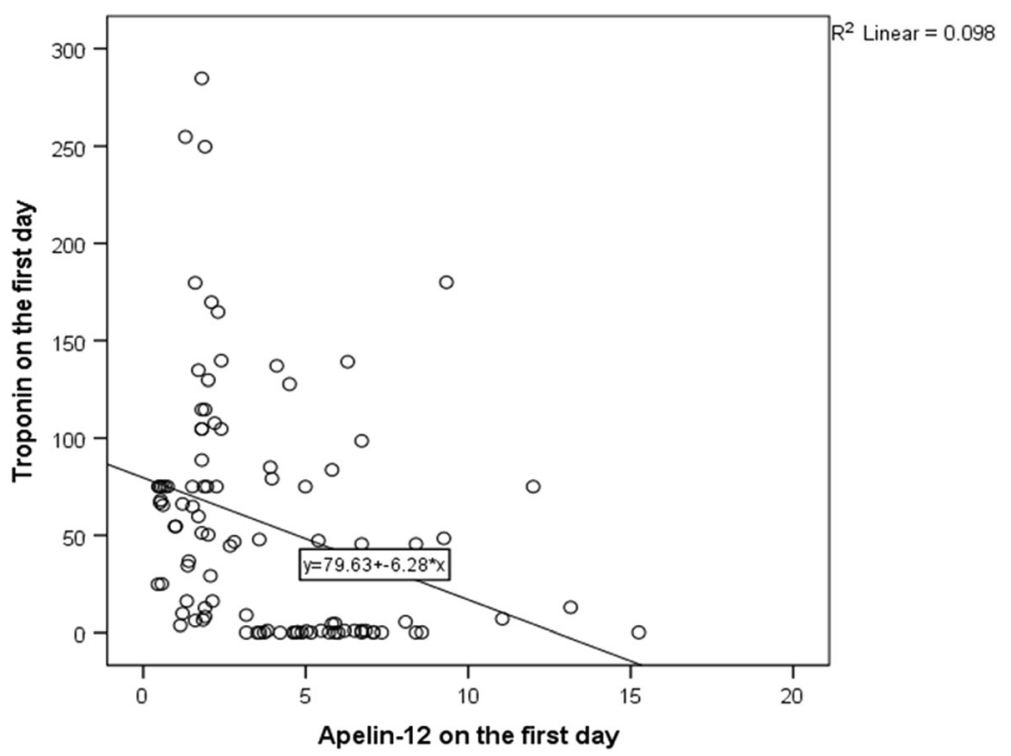

Fig. 2 Inverse correlation between apelin-12 and troponin levels in patients with STEMI

A receiver operating characteristic (ROC) curve plots the true positive rate against the false positive rate at different cut-off points. Table 2 presents the area under the curve values for biomarkers, and Fig. 4 presents the ROC curve for apelin-12 and MACE.

\section{Discussion}

In this study, we investigated the influence of apelin-12 on troponin levels and the rate of MACE in STEMI patients. The present study showed association between apelin-12 and troponin in the acute phase of myocardial

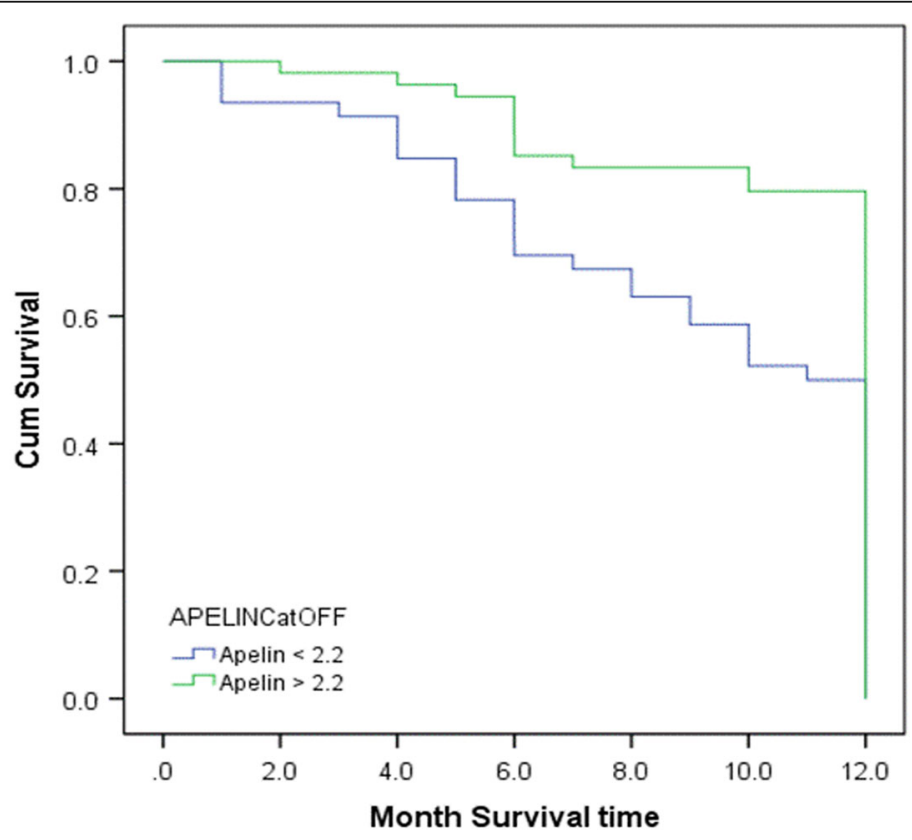

Number at risk

\begin{tabular}{|c|c|c|c|c|c|c|}
\hline Apelin $<2.2$ & 45 & 43 & 39 & 32 & 29 & 24 \\
\hline Apelin $>2.2$ & 53 & 53 & 52 & 46 & 45 & 43 \\
\hline
\end{tabular}

Fig. 3 Kaplan-Meier estimates showing lower rates of MACE recurrence among patients with apelin levels $>2.2$ compared to lower apelin levels $<2.2(p=0.002)$ 
Table 2 Area under the curve values for biomarkers

\begin{tabular}{lll}
\hline Biomarker & AUC $(95 \% \mathrm{Cl})$ & $P$-value \\
\hline Apelin 12 on the first day & $0.52(0.37-0.67)$ & 0.71 \\
Apelin 12 on the seventh day & $0.71(.58-0.84)$ & 0.004 \\
Troponin I on the first day & $0.48(0.33-0.63)$ & 0.8 \\
Troponin I on the seventh day & $0.41(0.27-0.55)$ & 0.25 \\
Creatine kinase & $0.48(0.33-0.63)$ & 0.84 \\
Creatine kinase-MB & $0.58(0.43-0.73)$ & 0.27 \\
NT-proBNP & $0.49(0.33-0.64)$ & 0.88 \\
C-reactive protein & $0.54(0.39-0.69)$ & 0.56 \\
\hline
\end{tabular}

Abbreviations: NT-proBNP N-terminal pro b-type natriuretic peptide

infarction, whereas rates of MACE after STEMI were expected based on values of apelin-12 in the non-acute phase. The findings of other studies have demonstrated efficiency of myocardial protection induced by apelin limiting myocardial infarction and its action as a regulatory peptide increasing cadiac contractility [30, 31].

In the acute phase of myocardial infarction, the atheromatous plaque in the lumen suffers from complete or incomplete acute block-up, which results in ischaemia in the myocardium. During hypoxia ( $24 \mathrm{~h}, 2 \% \mathrm{O} 2)$, apelin gene expression and secretion are increased through the activation of hypoxia inducible factor (HIF) [10, 32, 33]. Hypoxia requires a functional mitochondrial electron transport chain for the inhibition of prolyl hydroxylases and HIF stabilization [34]. Under anoxic conditions, the stabilization of HIF is preserved due to the lack of a functioning mitochondrial respiratory chain, and thus,

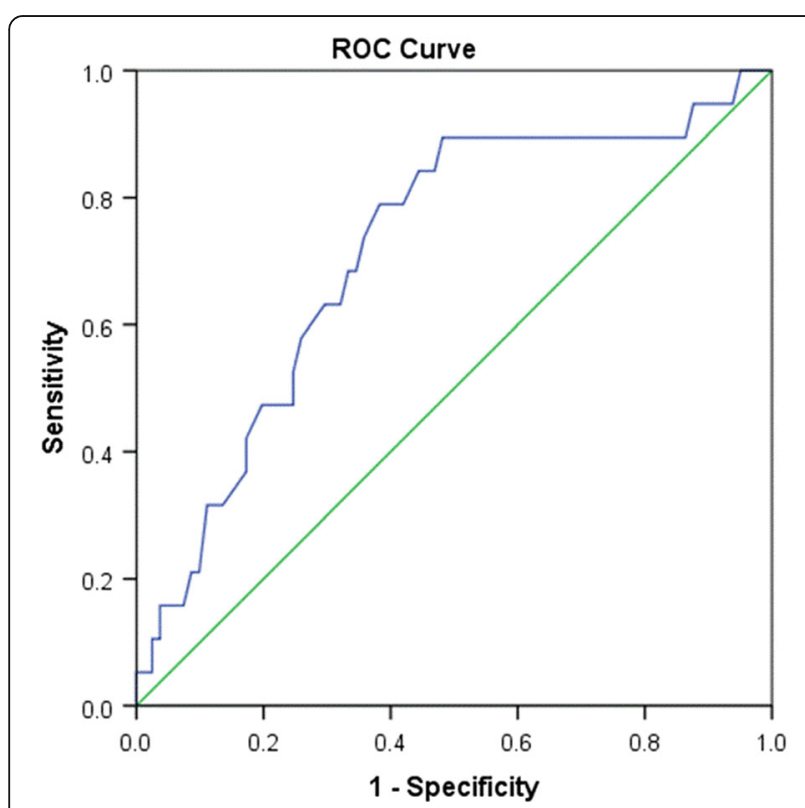

Fig. 4 ROC curve analysis of the apelin values on the seventh day for the prediction of MACE. AUC $=0.71(95 \% \mathrm{Cl}, 0.58-0.84), p=0.004$ the apelin gene is neither expressed nor is its expression increased [35].

Apelin activates its sites on troponin $\mathrm{I}$, regulating $\mathrm{Ca}^{2+}$ sensitivity and ATPase activity in the myocardium through protein kinase C [23, 24]. During ischaemia/infarction, phosphorylated TnI levels, $\mathrm{Ca}^{2+}$ sensitivity and ATPase activity are decreased in the myocardium, and subsequently, the elevated $\mathrm{Ca}^{2+}$ levels activate protease I (caplain I), leading to the proteolytic degradation of troponins and ventricular dysfunction [25-28]. The degree of association between apelin-12 and troponin I in the first day of the acute phase of STEMI was analysed with Spearman's correlation $=-0.40(p<0.001)$. The relationship between apelin-12 and troponin I was analysed by a regression analysis, predicting one variable from the other (Fig. 2).

The loss of apelin (APLN) clearly compromises the activation of the protective Akt/PI3K and extracellular signal-regulated kinase $1 / 2($ Erk1/2) signalling pathways both in vivo and ex vivo, resulting in increased myocardial damage and worsened heart function [36]. Low values of apelin in the non-acute phase of STEMI were associated with high rates of MACE after STEMI, with variability in the apelin values on the seventh day (Kruskal-Wallis test) based on major adverse cardiac events (MACE) that was significantly different $(p<0.012)$. A cut-off value for apelin-12 levels on the seventh day was set for the survival analysis, and a Kaplan-Meier curve was generated; the log-rank test for differences in survival resulted in a $p$ value of 0.002 . ROC curve analysis showed that the area under the curve was significantly different, with a $p$ value of 0.004 (Fig. 4 and Table 2).

The vision for the future is potential utility of apelin-12 measurement in STEMI patients as an additional risk stratification tool and possibility for the usage as a therapy.

We were aware of some limitations to our study. This observational study had a relatively limited number of patients. Apelin levels and correlation with troponin in non-STEMI acute chest pain differential admissions to the emergency department would be interesting as control group.

\section{Conclusion}

Apelin-12 influences troponin I levels in the acute phase of STEMI, whereas during the non-acute phase, low apelin levels were associated with a high rate of MACE.

Table 3 Take home messages

Apelin-12 influences troponin I levels in the acute phase of STEMI

A high rate of MACE after STEMI was characterized with low values of apelin during non-acute phase

$\mathrm{n}$ the future, potential utility of apelin-12 measurement in STEMI patients as an additional risk stratification tool and possibility for the usage as a therapy 


\section{Take home message}

\section{Table 3 presents take home messages.}

\begin{abstract}
Abbreviations
Akt/PI3K: phosphatidylinositol 3-kinase/protein kinase B; APJ: Angiotensin receptor like-1; APLN: Apelin; ATPase: Adenosine triphosphatase; DAG: Diacylglycerol; ECG: Electrocardiography;

EDTA: Ethylenediaminetetraacetic acid; ELISA: Enzyme-linked immunosorbent assay; Erk: Extracellular signal-regulated kinases; HIF: Hypoxia inducible factor; IP3: Inositol trisphosphate; LAD: Left anterior descending artery; LCX: Left circumflex; LMA: Left main artery; MACE: Major adverse cardiac events; NCX: $\mathrm{Na}^{+} / \mathrm{Ca}^{2+}$ exchanger; NHE: $\mathrm{Na}^{+} / \mathrm{H}^{+}$exchanger; NT-proBNP: N-terminal pro b-type natriuretic peptide; PIP2: Phosphatidyl inositol bisphosphate; PKC: Protein kinase C; PLB: Phospholamban; PLC: Phospholipase C; RCA: Right coronary artery; ROC: Receiver operating characteristic; RYRs: Ryanodine receptors; SD: Standard deviation; SERCA: Sarco/endoplasmic reticulum $\mathrm{Ca}^{2+}$ ATPase; STEMI: ST-Segment elevation myocardial infarction
\end{abstract}

\section{Acknowledgements}

We are grateful to the patients who participated in this study and for the follow-up data collection. We would like to thank the staff of the Dubrava University Hospital-Zagreb and the University Clinical Center of Kosova-Pristina for their assistance.

\section{Funding}

Not applicable.

\section{Availability of data and materials}

The data and materials of the study are only available from the corresponding author upon reasonable request.

\section{Authorship declaration}

All authors listed meet the authorship criteria according to the latest guidelines of the International Committee of Medical Journal Editors and are in agreement regarding the manuscript.

\section{Authors' contributions}

XK analyzed and interpreted data and was a major contributor in writing the manuscript and implementation of the study. BB analyzed the patient data and contributed in implementation of the study. MG analyzed the patient data and overview the study. DK analyzed the data and contributed in editing the manuscript. FJ analyzed the data and contributed in statistical interpretation. JV analyzed the patient data and overview the study. All authors read and approved the final manuscript.

\section{Ethics approval and consent to participate}

The study was approved by the institutional ethics committee of Dubrava University Hospital-Zagreb and the University Clinical Center of Kosova-Pristina. Written informed consent was obtained from all patients before inclusion in the study.

\section{Consent for publication}

Not applicable.

\section{Competing interests}

The authors declare that they have no competing interests.

\section{Publisher's Note}

Springer Nature remains neutral with regard to jurisdictional claims in published maps and institutional affiliations.

\section{Author details}

${ }^{1}$ Clinical Hospital Dubrava, Zagreb, Republic of Croatia. ${ }^{2}$ University Clinical Center of Kosova, Mother Theresa n.n, 10000 Prishtina, Republic of Kosovo.
Received: 24 May 2017 Accepted: 14 July 2017

Published online: 20 July 2017

\section{References}

1. Chandrasekaran B, Dar O, McDonagh $\mathrm{T}$. The role of apelin in cardiovascular function and heart failure. European J Heart Fail. 2008;10(8):725-32.

2. Babuin L, Jaffe A. Troponin: the biomarker of choice for the detection of cardiac injury. CMAJ. 2005;173(10):1191-202.

3. Clerico A, Emdin M. Diagnostic accuracy and prognostic relevance of the measurement of cardiac natriuretic peptides: a review. Clin Chemi. 2004:50(1):33-50.

4. Tatemoto K, Hosoya M, Habata Y, Fujii R, Kakegawa T, et al. Isolation and characterization of a novel endogenous peptide ligand for the human APJ receptor. Biochem Biophys Res Communs. 1998;251(2):471-6.

5. BF OD, Heiber M, Chan A, Heng HH, Tsui LC, et al. A human gene that shows identity with the gene encoding the angiotension receptor is located on chromosome 11. Gene. 1993;136(1-2):355-60.

6. Japp A, Newby D. The apelin-APJ system in heart failure: pathophysiologic relevance and therapeutic potential. Biochem Pharmacol. 2008;75(10):1882-92.

7. Szokodi I, Tavi P, Földes G, Voultilainen-Myllylä S, Ilves M, et al. Apelin, the novel endogenous ligand of the orphan receptor APJ, regulates cardiac contractility. Circ Res. 2002;91(5):434-40.

8. Neves SR, Ram PT, Lyengar R. G protein pathways. Science. 2002:296(5573):1636-9.

9. Karmazyn M, Gan XT, Humphreys RA, Yoshida H, Kusumoto K. The myocardial $\mathrm{Na}(+)-\mathrm{H}(+)$ exchange: structure, regulation, and its role in heart disease. Cir Res. 1999;85(9):777-86.

10. Ronkainen VP, Ronkainen JJ, Hänninen SL, Leskinen H, Ruas JL, et al. Hypoxia inducible factor regulates the cardiac expression and secretion of apelin. FASEB J. 2007;21(8):1821-30.

11. Hus-Citharel A, Bodineau L, Frugière A, Joubert F, Bouby N, Llorens-Cortes C. Apelin counteracts vasopressin-induced water reabsorption via cross talk between apelin and vasopressin receptor signaling pathways in the rat collecting duct. Endocrinology. 2014;155(11):4483-93.

12. Taheri S, Murphy K, Cohen M, Sujkovic E, Kennedy A, et al. The effects of centrally administered apelin-13 on food intake, water intake and pituitary hormone release in rats. Bioch Biophys Res Commnun. 2002:291(5):1208-12.

13. Zhang Z, Yu B, Tao GZ. Apelin protects against cardiomyocytes apoptosis induced by glucose deprivation. Chin Med J. 2009;122(19):2360-5.

14. Pang H, Han B, Li ZY, Fu Q. Identification of molecular markers in patients with hypertensive heart disease accompanied with coronary artery disease. Genet Mol Res. 2015;14(1):93-100.

15. Gonzalez M, Porterfield C, Eilen D, Marzouq RA, Patel HR, et al. Quartiles of peak troponin are associated with long-term risk of death in type 1 and STEMI, but not in type 2 or NSTEMI patients. Clin Cardiol. 2009;32(10):575-83.

16. Polanczyk C, Lee T, Cook E, Walls R, Wybenga D, et al. Cardiac troponin I as a predictor of major cardiac events in emergency department patients with acute chest pain. J Am Coll Cardiol. 1998;32(1):8-14.

17. Hall TS, Hallén J, Krucoff MW, Roe MT, Brennan DM, et al. Cardiac troponin I for prediction of clinical outcomes and cardiac function through 3-month follow-up after primary percutaneous coronary intervention for ST-segment elevation myocardial infarction. Am Heart J. 2015;169(2):257-65.

18. Keller T, Zeller T, Peetz D, Tzikas S, Roth A, et al. Sensitive troponin I assay in early diagnosis of acute myocardial infarction. $\mathrm{N}$ Engl J Med. 2009;361(9):868-77.

19. Javed U, Aftab W, Ambrose JA, Wessel RJ, Mouanoutoua M, et al. Frequency of elevated troponin I and diagnosis of acute myocardial infarction. Am J Cardiol. 2009;104(1):9-13.

20. Auguardo C, Scalise F, Manfredi M, Casali V, Novelli E, et al. The prognostic role of troponin I elevation after elective percutaneous coronary intervention. J Cardiovasc Med (Hagerstown). 2015;16(3):149-55.

21. Yamamura $K$, Steenbergen $C$, Murphy E. Protein kinase $C$ and preconditioning: role of sarcoplasmic reticulum. Am J Physiol Heart Circ Pysiol. 2005;289(6):2484-90.

22. Wang C, Du JF, Wu F, Wang HC. Apelin decreases the SR ca $2+$ content but enhances the amplitude of [ca 2+]i transient and contractions during twitches in isolated rat cardiac myocytes. Am J Physiol Heart Circ Physiol. 2008:294(6):2540-6.

23. Farkasfalvi K, Stagg M, Coppen S, Siedlecka U, Lee J, et al. Direct effects of apelin on cardiomyocyte contractility and electrophysiology. Biochem Biophys Res Commun. 2007;357(4):889-95. 
24. Pi YQ, Zhang D, Kemnitz KR, Wang $H$, Walker JW. Protein kinase $C$ and a sites on troponin I regulate myofilament ca 2+, sensitivity and ATPase activity in the mouse myocardium. J Physiol. 2003;552(Pt3):845-57.

25. Bodor GS, Oakeley AE, Allen PD, Crimmins DL, Ladenson JH, et al. Troponin phosphorylation in the normal and failing adult human heart. Circulation. 1997;96(5):1495-500.

26. Wijnker PJ, Murphy AM, Stienen GJ, van der Velden J. Troponin I phosphorylation in human myocardium in health and disease. Neth Heart J. 2014;22(10):463-9.

27. Gao WD, Liu Y, Mellgren R, Marban E. Intrinsic myofilament alterations underlying the decreased contractility of stunned myocardium. A consequence of ca 2+-dependent proteolysis? Circ Res. 1996;78(3):455-65.

28. Van der Laarse A. Hypothesis: troponin degradation is one of the factors responsible for deterioration of the left ventricular function in heart failure. Cardiovasc Res. 2002:56(1):8-14.

29. Windecker S, Kolh P, Alfonso F, Collet JP, Cremer J, et al. ESC/EACTS guidelines on myocardial revascularizations: the task force on myocardial revascularization of the European Society of Cardiology (ESC) and the European association for cardiothoracic surgery (EACTS) developed with the special contribution of the European Association of Percutaneous Cardiovascular Intervetions (EAPCI). Eur Heart J. 2014;35(46):2541-619.

30. Rastaldo R, Cappello S, Folino A, Berta GN, et al. Apelin-13 limits infarct size and improves cardiac postischemic mechanical recovery only if given after ischemia. Am J Physiol Heart Circ Physiol. 2011;300(6):2308-15.

31. Japp AG, Cruden NL, Barnes G, van Gemeren N, Mathews J, et al. Acute cardiovascular effects of apelin in humans: potential role in patients with chronic heart failure. Circulation. 2010;121(16):1818-27.

32. Jianqiang $P$, Ping Z, Xinmin F, Zhenhua $Y$, Ming Z, et al. Expression of hypoxia-inducible factor 1 alpha ameliorate myocardial ischemia in rat. Biochem Biophys Res Commun. 2015;465(4):691-5.

33. Cheng C, Li P, Wang YG, Bi MH, Wu PS. Study on the expression of VEGF and HIF-1a in infarct area of rats with AMI. Eur Rev Med Pharmacol Sci. 2016:20(1):115-9.

34. Schroedl C, McClintock DS, Budinger GRS, Chandel NS. Hypoxic but not anoxic stabilization of HIF-1a requires mitochondrial reactive oxygen species. Am J Physiol Lung Cell Mol Physiol. 2002;283(5):L922-31.

35. Vaux EC, Metzen E, Yeates KM, Ratcliffe PJ. Regulation of hypoxia-inducible factor is preserved in the absence of a functioning mitochondrial respiratory chain. Blood. 2001:98(2):296-302.

36. Wang W, McKinnie SM, Patel VB, et al. Los of Apelin exacerbates myocardial infarction adverse reomdeling and ischaemia reperfusion injury: therapeutic potential of synthetic Apelin analogues. J Am Heart Assoc. 2013;2:e000249.

\section{Submit your next manuscript to BioMed Central and we will help you at every step:}

- We accept pre-submission inquiries

- Our selector tool helps you to find the most relevant journal

- We provide round the clock customer support

- Convenient online submission

- Thorough peer review

- Inclusion in PubMed and all major indexing services

- Maximum visibility for your research

Submit your manuscript at www.biomedcentral.com/submit 